\title{
Developing an Assessment Instrument for Integrated Science Process Skill (ISPS) in Fundamental Chemistry Course
}

\author{
${ }^{1}$ Noviyanti Sarapina, ${ }^{2} \mathrm{M}$. Adlim, and ${ }^{3}$ Ibnu Khaldun \\ Science Education Master's Program, University Syiah Kuala, Banda Aceh, Indonesia ${ }^{1}$ \\ Departement of Chemistry Education, University Syiah Kuala, Banda Aceh, Indonesia ${ }^{2,3}$ \\ \{Sarapina19@yahoo.co.id¹,Adlim@unsyiah.ac.id², Ibnukhdn@yahoo.com³ $\}$
}

\begin{abstract}
In this research, the development of the instrument integrated science process skill (ISPS) in a basic chemistry course in the form of multiple choices test. This study a Research and Development $(R \& D)$ with 3 stages, starting from; 1) the problem identification, examines the theoretical study and needs analysis, 2) the composing activities including planning, group meeting, expert validation, readability test, testing of small group and initial product, 3) evaluation activities, first field trial, product revisions, second field trial, analysis of items and final product revisions. The research subjects were students of $3^{\text {rd }}$ semester (pre-service teachers) chemistry education department. Data analysis uses descriptive percentages and quantitative analysis. The ISPS aspects used are formulating hypotheses, defining operations, interpreting data/graphs, identifying/controlling variables and designing experiments. Fifty-five (55) questions have been developed but after analysis discrimination index, difficulty index, validity, reliability analysis only 31 valid test items for ISPS instruments with a reliability value of 0.967 the criteria are very high.
\end{abstract}

Keywords: ISPS, Thinking Skill, Discrimination Index, Difficulty Index, Validity, Reliability

\section{Introduction}

Education in the era of industrial revolution 4.0 has been re-oriented to accommodate learning environment for developing thinking skill rather than memorizing facts. One of the essential skills is critical thinking [1]. The manifestation of critical thinking skill in science learning might be part of science process skills (SPS). Such skill is crucial for students to apply knowledge in society and necessary in daily life [2]-[4]. SPS is a science process skill that includes cognitive and motorists which trains reasoning skills [5]-[8]. It is also known as procedural, experimental, scientific inquiry and thinking skills, which might be drilled through laboratory activities [2], [9], [10]. Basic science process skills (BSPS) were usually experienced in primary school levels and the integrated science process skills (ISPS) can be accomplished by higher level school students [11]. ISPS is the development of basic SPS [8], [12]. which composes five aspects, namely formulating hypotheses, defining operations, interpreting data/graphs, identifying/controlling variables and designing experiments [4], [7], [9], [13], [14]. Assessing the ISPS is not simply to measure the cognitive aspects but it also to examine the thinking skill process. ISPS is formulated as a scenario within a text and followed by several multiple choice questions. Therefore ISPS instrument has not been much available in literature especially for fundamental chemistry course [6], [15].

\subsection{Problem of Research}

ISPS assessment is crucial at the beginning of the lecture because it can diagnose the learning objective achievement of the lab practical and other learning activities. Conventional lab practical work has not been accommodated all science process skill especially the skill of designing experiment is very rare in student lab worksheet [16]. Such skill is, even more, changing for in-service teachers in a rural area [17]. Therefore this study is to develop valid ISPS instruments for basic chemistry courses to evaluate new student ISPS.

\subsection{Research Focus}

Research on the developing SPS test instruments has been carried out by several researchers. Feyzioglu, Demirdag, Akyildiz, \& Altun [18] 'developed SPS test instruments on environmental chemical technology in the form of 30 multiple choice questions with a reliability score of 0.83 . Similar research models regarding the 
validity and reliability tests also have been existed in the literature including ISPS for natural science course [14], [19]-[21]. Some ISPS was composed in the form of essay test [12], [22]. While the focus of this study is to develop a valid and reliable ISPS instrument in multiple-choice forms that can be used as a test tool to find out ISPS students. Specialized as a tool to measure ISPS in the student's basic chemistry courses at the beginning of the lecture, evaluating practical activities and other learning activities.

\section{Methodology of Research}

The Subjects were 55 third semester students majoring in chemistry education at University. ISPS was developed by verifying the previously thesis on developing ISPS for science [16], [23]. The design of the instrument development was carried out by adapting the design of [12], [23], [24] and the process was displayed in Figure 1. ISPS instrument was developed in 55 of multiple choice questions as the initial product. The questions were given to 55 pre-service teachers (third semester of teacher training university-students) with voluntary sampling. The generated data is analyzed with the help of a test item analysis program developed by [25].

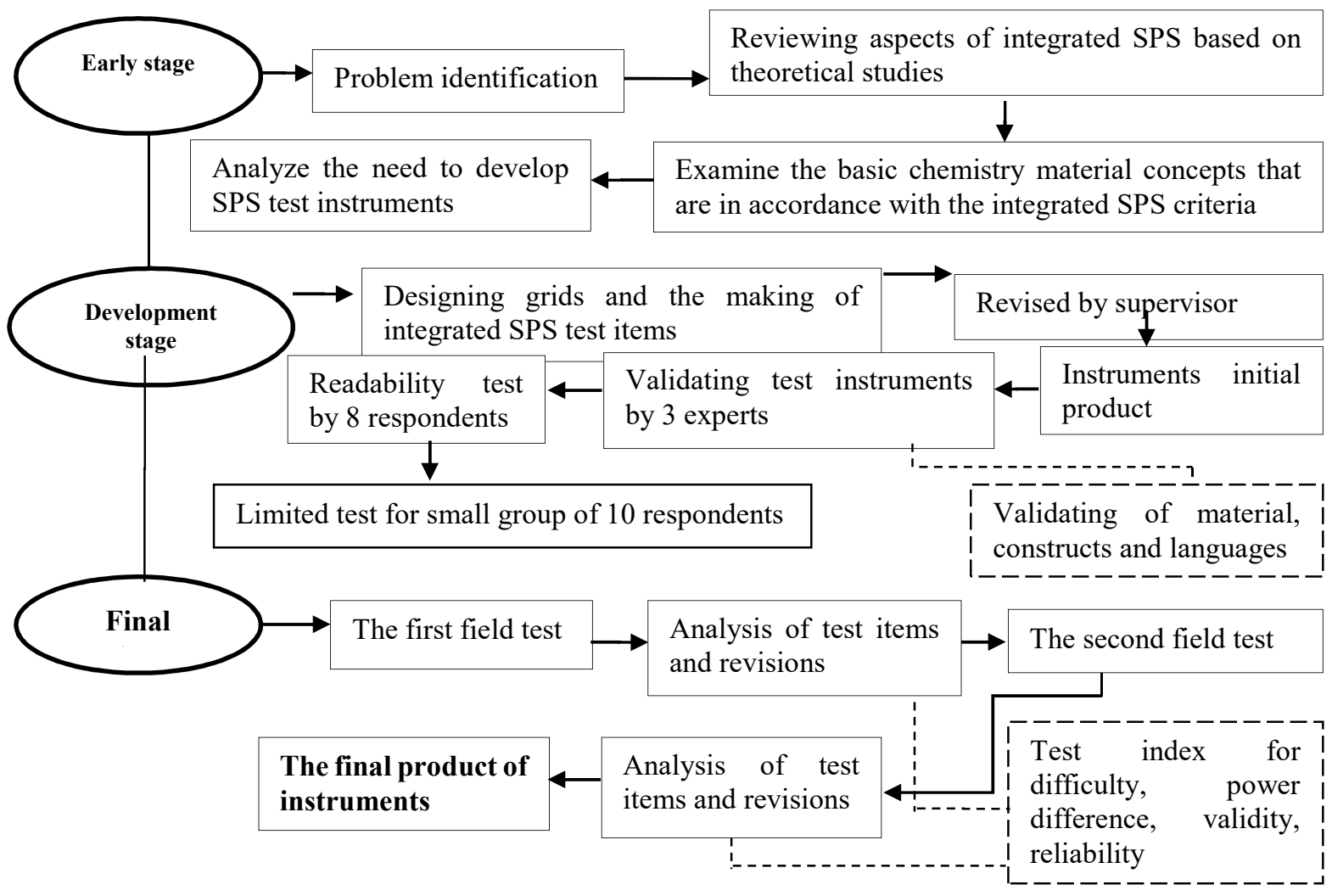

Figure 1. The design of the study. 


\subsection{Data Analysis}

The content ISPS instrument was validated 3 experts (chemistry professor and science teaching) to evaluate each test time that representing ISPS aspects (formulating hypotheses, defining operations, interpreting data/graphs, identifying/ controlling variables and designing experiments) and also language. The validation sheets were analyzed using descriptive analysis that is calculating in percentage representation [15]. After revising several times according to expert suggestion then, the instrument was tested on 55 third-semester chemistry students (preservice teachers). Data was analyzed to search the index of difficulty (P) (range score of $0.30<$ $\mathrm{P} \leq 0.70$ ), the moderate level of difficulty was chosen. The discrimination index $(\mathrm{P})$ was taken in score range of $0.20<\mathrm{P} \leq 1.00$; the validity test was calculated on $0.20<\mathrm{r}_{\mathrm{xy}}<1.00$ and reliability test was conducted using formula of Kuder Richardson 20 with score range of 0.79 1.00 [7], [8], [14], [18], [19].

\section{Results and Discussion}

The content validation data obtained by analyzing the validation sheets, the data were grouped into material validation, contract validation and language validation [26]. This indicated that the assessment format is suitable, the subject matter is clearly formulated (appropriateness of the conceptual, the ISPS aspects), language use (Indonesian) is appropriate. The validation score on material and language aspects were in the level of very accurate ( $>80 \%)$ and the construction aspect was considered accurate or valid as shown in Table 1.

Table 1. The result of the validation of ISPS test instrument by the experts.

\begin{tabular}{ccc} 
Aspect & Value & Criteria \\
\hline Material & $81.72 \%$ & Very accurate \\
\hline Construction & $79.83 \%$ & Accurate \\
\hline Language & $82.15 \%$ & Very accurate \\
\hline Validity average total score & $81.24 \%$ & Very accurate
\end{tabular}

Based on the data in Table 1, the results of the validation of the test questions by the experts as a whole in terms of material, construction and language are in very accurate or valid with the average value is $81.24 \%$. However, a small improvement and revision were carried out on a number of questions, one of which was an SPS question of identifying/controlling variables aspect. Improvements were made because the description of the questions presented was less clearly formulated and raised ambiguous questions. Therefore, the questions were fixed but with the same answers, also the alternative answer choices provided is not right. The following are examples of questions before and after revision can be seen in Table 2. Furthermore, from the five aspects of integrated SPS that were revised by the experts, some questions were changed and also reviewed, the results of the integrated SPS questions recapitulation can be seen in Table 3.

Table 2. The example of ISPS question before and after revision

Question before revision
A student conducted a simple trial by storing water in an opened bottle and a closed bottle with the same amount of water. After a few days, it turns out that the 
Question after revision volume water in the opened bottle is reduced, while the water in the closed bottle remains the same volume. At a certain temperature, the water will evaporate and will form a gas (water vapor), the vapor will condense and form liquid these are called dynamic equilibrium. The water in the closed bottle will evaporate and condense in the bottle and flow again to the bottle. How do students know the relationship between air temperature and the amount of water vapor that condenses and the cause of this dynamic equilibrium?

a. The water in the opened bottle decreases due to the influence of the temperature.

b. The water in the opened bottle evaporates and condenses out of the bottle so the amount of water in the bottle will decrease.

c. The water in the closed bottle remains the same because the environment temperature does not influence the water.

d. The water in the closed bottle remains the same because of the evaporation and condensation process.

A student has just learned that air contains water vapor in the form of gas. The gas turns into the water at a low temperature. He took 5 equal-sized formulated milk cans and filled in with a number of an ice cube in different pieces. Each of the cans is placed above the funnel that can collect the dew into the measuring cup. How do students know the relationship between air temperature and the amount of moisture that condenses?

a. Measure the volume of water produced and compared it with the initial temperature of each can.

b. Observe the five cans and compare the amount of water vapor produced.

c. Measure the temperature of each can and compare the amount of water vapor produced in each.

d. Measure the volume of the dew collected at certain intervals on each can and record the temperature outside of each can.

Table 3. ISPS question recapitulation result revised by the experts.
ISPS aspect
The number of
The number of questions before questions after
Information revision revision

\begin{tabular}{|c|c|c|c|}
\hline Determining the hypothesis & 9 & 9 & 4 questions are revised \\
\hline Defining the operation & 11 & 11 & $\begin{array}{l}6 \text { questions are changed and } 2 \\
\text { questions are revised }\end{array}$ \\
\hline $\begin{array}{l}\text { Identifying and } \\
\text { controlling/the variable }\end{array}$ & 10 & 10 & $\begin{array}{l}3 \text { questions are changed and } 1 \\
\text { questions are revised }\end{array}$ \\
\hline $\begin{array}{l}\text { Interpreting the data/ } \\
\text { reading the chart }\end{array}$ & 12 & 12 & 4 questions are changed \\
\hline Designing experiments & 13 & 13 & 4 questions are changed \\
\hline
\end{tabular}

Next, the readability test carried out by 8 respondents, the aim is to know the suitability of the language and the understanding of the respondents to the sentences presented [24]. This is done to make it easier for respondents to understand the questions. This test uses an answer sheet that contains opinions and suggestions about the instrument, the procedure is that the respondent reads the questions and gives opinions, criticisms, suggestions if there are languages and sentences that are difficult to understand. Based on the readability test results of several respondents, the language of the questions presented is easy to understand, the story-type question makes it easier to understand, the use of systematic procedural questions makes it easier to examine the questions and the case used in the question based on daily life hence it triggers 
to analyze the problem. The suggestions presented by respondents are the text presented in the question is too long it takes time to read it. It is necessary to know the questions of measuring integrated SPS aims to find out thinking skill, therefore the questions presented are long because the form of the SPS question is analyzing problems in daily life that cover basic chemistry course. So, the SPS questions that developed are more procedural or practical questions and presents problems [10].

\subsection{The First Field Test}

Difficulty index test serves to determine the level of difficulty of the test questions. The criteria for good questions are questions that are not too easy and not too difficult [8]. First stage test was applied for 55 respondents who chemistry undergraduate students of teacher training. Of the 55 questions tested, there were 6 easy, 40 medium and 9 difficult questions. The easy question has a difficulty index of $0.71-1.00$, moderate $0.70-0.31$ and difficult from $0.30-0.00$. Then, the difficulty index of the five aspects of ISPS questions developed is at an average of $>$ 0.31 and $<0.70$. The questions that considered by a student the most difficult was in test items of "designing the experiment" with difficulty index of 0.362 , the easy one is the aspect of "identifying/controlling the variable" with difficulty index of 0.571 .

Discrimination index test analysis aims to find how the question is able to distinguish highcapability and low-ability samples to have opportunity to answer correctly [8]. From the discrimination index, there were 21 questions with deficient criteria, 10 questions are enough, 21 good questions and 3 questions with very good. Questions that are categorized as deficient with a score of $\geq 0,190$ were rejected. This occurs because the questions developed are not able to measure smart respondents with less intelligent respondents. The effectiveness of deception is also very important to determine the level of accuracy and understanding of respondents. The answer choices function to see the understanding of respondents in analyzing the questions. Proper deception provisions are chosen $\geq 5 \%$, means that the deceiver functions if at least 3 respondents respond to the same answer choices from the total of respondents.

From the validity analysis, there were 17 questions that had very low criteria $(0.20)$ that means consistency and accuracy of the questions were invalid. There were 12 questions that have low validity $(>0.20)$ and 7 questions were medium validity $(0.40), 15$ questions were highly valid $(>0.60)$ and 4 questions were very high validity $(>0.80)$. The reliability analysis shows a very high score of 0.887 which means that the ISPS instruments are very reliable. Therefore only 34 out of 55 questions were selected due to high reliability $(0.887)$ for test items of the ISPS assessment instrument. Among 34 questions, 3 of which has been revised for the second times for re-use. In average it took 90 minutes for respondents to complete all questions.

\subsection{The Second Field Test}

The second field test was applied for 51 respondents who chemistry undergraduate students of teacher training with 34 questions tested. The difficulty index of the instrument was $>0.31$ (moderate) that is ideal for a standardized instrument. The 3 questions were considered difficult (the score 0.30) and the easy question was none. Distribution of the difficulty index in each aspect of ISPS was tabulated in Figure 2. 


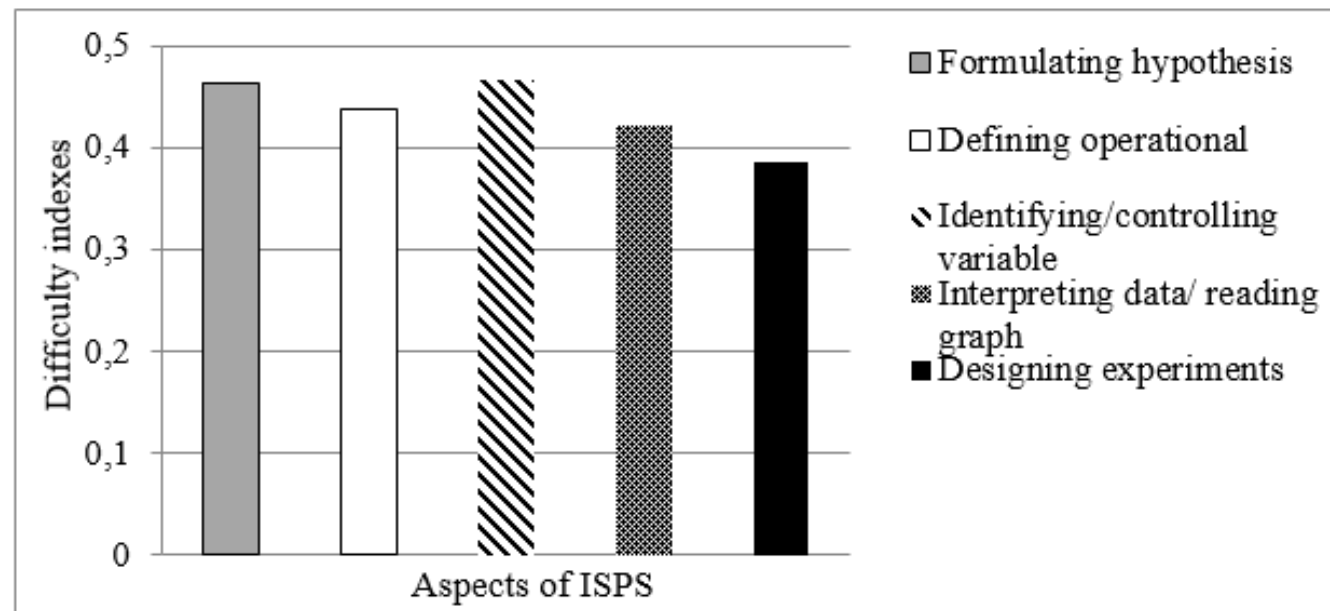

Figure 2. The distribution of difficulty indexes for each aspect of ISPS instrument

Figure 2, shows that the lowest difficulty index is in the aspect of designing the experiment with a value of 0.385 , which means that this problem was the most difficult compared to other and the aspect of identifying/controlling the variable was considered the easiest with a value of 0.467 This finding consistent with the previous study where designing experience is the most difficult for students although for the subject of high school science [16][27]. Also reported that the ISPS aspect on identifying/control the variable is considered a moderate difficulty for the respondents. This is because regular science practicum already contained some exercise for students to drill skill in identifying/controlling variables but an exercise in designing experiment are very rare in conventional science practical works.

Discrimination index in the second test found 3 questions (bad) 2 question (sufficient), 21 question (good) and 8 questions (very good), therefore 29 questions were chosen. The choice of answers used all functioned while there were 5 questions which were not good enough that means the answer choices presented were not functioning, therefore revisions were made before the final product was obtained. Validity test show 14 questions have highly valid, 15 questions are valid, 3 question is sufficient and 3 questions were poor. Reliability test found 34 questions have high reliability $(0.967)$. There were 31 questions that have moderate difficulty index and 3 questions were considered too difficult and it was rejected. Those 31 selected questions distributed in five aspects of ISPS as shown in Table 4.

Table 4. Number of valid ISPS question items.

\begin{tabular}{llc}
\multicolumn{1}{c}{ ISPS aspects } & \multicolumn{1}{c}{ The question number } & Total of questions \\
\hline Formulating hypothesis & $3,6,17,23,27$ & 5 \\
\hline Defining operational & $5,8,11,12,14,15,18,24$ & 8 \\
\hline Identifying/controlling variable & $16,19,22,29,30$ & 5 \\
\hline Interpreting data/ reading graph & $1,2,4,9,21,28$ & 6 \\
\hline Designing experiments & $7,10,13,20,25,26,31$ & 7 \\
\hline Total & & 31
\end{tabular}




\section{Conclusions}

Based on the results of this study it can be concluded, the test questions was developed is good with an average index level of difficulty is medium, good power difference, and high validity. This means the instrument is high of quality and meets the standards to be used. The level of reliability of the instrument increased from the first test 0,887 becomes 0,967 in the second test which was on very high criteria, means that the instrument was very reliable. Also, obtained 31 test questions of good criteria consisting of 5 aspects, which could be used to measure integrated SPS in the basic chemistry course.

\section{REFERENCES}

[1] A. A. Hussin, "Education 4.0 made simple: Ideas for teaching," Int. J. Educ. Lit. Stud., 2018.

[2] R. E. Irwanto and A. K. Prodjosantoso, "Undergraduate students science process skill in terms of some variables: A perspektive from indonesia," J. Balt. Sci. Educ., vol. 17, no. 5, pp. 751-764, 2018.

[3] E. Gaigher, E. Baloyi, and M. Kazeni, "Effectiveness of individual and group investigations in developing integrated science inquiry skills," South African J. Educ., vol. 38, no. 3, pp. 1-12, 2018.

[4] Zulirfan, M. Rahmad, Yennita, N. Kurnia, and M. S. Hadi, "Science process skills and attitudes toward science of lower secondary students of merbau island: A preliminary study on the development of maritime-based contextual science learning media," $J$. Educ. Sci., vol. 2, no. 2, pp. 90-99, 2018.

[5] C. Kruea-In, N. Kruea-In, and W. Fakcharoenphol, "A study of thai in-service and preservice science teachers' understanding of science process skills," Procedia - Soc. Behav. Sci., 2015.

[6] N. D. Kahar and S. S. Sani, "Science process skills acquisition level among form two students in one district of Sabah," J. Res. Policy Pract. Teach. Teach. Educ., vol. 8, no. 1, pp. 32-44, 2018.

[7] W. Lati, S. Supasorn, and V. Promarak, "Enhancement of learning achievement and integrated science process skills using science inquiry learning activities of chemical reaction rates," Procedia - Soc. Behav. Sci., 2012.

[8] J. S. Rabacal, "Test of science process skills of biology students towards developing of learning exercises," Asia Pacific J. Multidiscip. Res., vol. 4, no. 44, pp. 9-16, 2016.

[9] T. Jeenthong, P. Ruenwongsa, and N. Sriwattanarothai, "Promoting integrated science process skills through betta-live science laboratory," Procedia-Soc. Behav. Sci., 2014.

[10] A. H. Zeidan and M. R. Jayosi, "Science process skills and attitudes toward science among palestinian secondary school students," World J. Educ., vol. 5, no. 1, pp. 13-24, 2015.

[11] A. Gürses, S. Çetinkaya, Ç. Doğar, and E. Şahin, "Determination of levels of use of basic process skills of high school students," Procedia - Soc. Behav. Sci., vol. 191, pp. 644-650, 2015.

[12] Suyanta, L. E. Widjajanti, E. Rohaeti, A. R. P. Sari, and S. R. D. Astuti, "Exploring item validity: Critical-science process skills integrated assessment instrument on electrolyte solution and acid base matter," Int. J. Sci. Technoledge, vol. 5, no. 1, 2017.

[13] W. Y. Beaumont and K. Soyibo, "An analysis of high school students' performance on five integrated science process skills," Res. Sci. Technol. Educ., 2002. 
[14] E. H. M. Shahali and L. Halim, "Development and validation of a test of integrated science process skills," Procedia - Soc. Behav. Sci., vol. 9, pp. 142-146, 2010.

[15] K. G. Tobin and W. Capie, "Development and validation of a group test of integrated science processes," J. Res. Sci. Teach., vol. 19, no. 2, pp. 133-141, 1982.

[16] M. Nuzulia, Adlim and Nurmalia, "Analysis of applicability the conventional laboratory practical manuals on pre-service teachers' integrated science process skills," J. Turkey Sci. Educ., 2019.

[17] M. Adlim et al., "Assesing chemistry-learning ccompetencis of students in isolated rural senior high school by using the national examination: A case study of simeulue island, Indonesia," Int. J. Sci. Math. Educ., 2014.

[18] B. Feyzioglu, B. Demirdag, M. Akyildiz, and E. Altun, "Developing a science process skills test for secondary students: Validity and reliability study," Educ. Sci. Theory Pract., vol. 12, no. 3, pp. 1899-1906, 2012.

[19] J. C. Burns, J. R. Okey, and K. C. Wise, "Development of an integrated process skill test: Tips II," J. Res. Sci. Teach., 1985.

[20] M. Hodosyova, J. Utla, M. Vanyova, P. Vnukova, and V. Lapitkova, "The development of science process skills in physics education," Procedia - Soc. Behav. Sci., vol. 186, pp. 982-989, 2015.

[21] B. K. Temiz, M. F. Tasar, and M. Tan, "Development and validation of a multiple format test of science process skills," Int. Educ. J., vol. 7, no. 7, pp. 1007-1027, 2008.

[22] F. Karsli and Ç. Şahin, "Developing worksheet based on science process skills: Factors affecting solubility," Asia-Pacific Forum Sci. Learn. Teach., vol. 10, no. 1, pp. 1-12, 2009.

[23] K. M. M. Monica, "Development and validation of a test of integrated science process skills for the futher education and training learners," South Africa: of University Pretoria., 2005.

[24] F. G. Dillashaw and J. R. Okey, "A test of the integrated science process skills for secondary science student," 1980.

[25] Khaldun I., "Program analisis butir soal dan penilaian hasil belajar," Universitas Syiah Kuala: Banda Aceh, 2016.

[26] E. Aydinli, I. Dökme, Z. K. Ünlü, N. Öztürk, R. Demir, and E. Benli, "Turkish elementary school students' performance on integrated science process skills," Procedia - Soc. Behav. Sci., vol. 15, pp. 3469-3475, 2011.

[27] Nuzulia, Adlim, and C. Nurmaliah, "Curriculum relevance and undergraduate students' integrated science process skills in chemistry, physics, biology and math majors," $J$. Pendidik. Sains Indones., vol. 5, no. 1, pp. 120-126, 2017. 